\title{
PERSPECTIVES FOR THE PRODUCTION OF COSMETIC OILS BASED ON THE PLANT COMPIONENTS
}

\author{
PhD Guleishvili Nino, \\ PhD Gabidzashvili Manana, \\ Professor Inga Bochoidze \\ Akaki Tsereteli State University \\ 4600 Kutaisi, Tamar Mepe \#59, Georgia \\ Manana.gabidzashvili@atsu.edu.ge \\ Nino.guleishvili@atsu.edu.ge
}

Abstract

The use of the natural plant components (fatty oils) and biologically active additives allows for balancing the formulation for cosmetic oils. When using biologically active supplements, the skin is rich in all the necessary nutrients that help to achieve the desired effect. When using biologically active additives, the skin is enriched with all the essential nutrients that help to achieve the desired effect.

Research covered rosehip fruits wild-growing in western Georgia. To obtain extract from raw materials, we used the superfluid $\mathrm{CO}_{2}$ extraction method. We obtained oil with yield ranging from 8.12 to $10.17 \%$, whose refractive index is 1,4782 units, and the extract rich in phenolic compounds, with total phenols $-3032 \mathrm{mg} / 100 \mathrm{~g}$ and total flavonoids $1501 \mathrm{mg} / 100 \mathrm{~g}$ on dried basis.

The synthetic components contained in cosmetic oils (butylhydroxytoluene, phenoxyethanol, etc.) adversely affect the skin condition and human health, provoking allergic reactions, irritations and redness.

The use of natural plant ingredients (fatty oils) and biologically active additives (extracts, vitamins, essential oils) balances the formulation of cosmetic oils. When using biologically active additives, the skin is enriched with all the essential nutrients that help to achieve the desired effect (restoring the skin's $\mathrm{pH}$ balance, cell renewal, the skin tonicity, structure recovery, etc.).

In its composition, vegetable oils are similar to intracellular lipids. The composition of lipids is as follows: fatty acids (triglycerides), cholesterol and ceramides (fatty acid+sphingosine). Vegetable oils that balance or fill fatty acids in the lipid layer, prevent dewatering and destruction of the deep skin structure; they can maximally supply the skin with vitamins, essential fatty acids, phytosterols and other essential nutrients required for the 
preservation of the skin's barrier function. Vegetable oils are the main source of unsaturated fatty acids (Omega-3, Omega-6 and Omega-9) [1].

Vegetable extracts enrich the skin with various nutrients, helping to root out the adverse environmental factors and age-specific skin changes, improving its appearance. Vegetable extracts contain various useful substances (vitamins, flavonoids, essential oils, microelements, etc.) that counteract the initial signs of skin aging, stimulate metabolic activity and structural proteins of the skin such as collagen and elastin [3,4].

Due to high permeability and versatile cosmetic action of the skin covering (normalizing blood circulation, stimulating cell renewal, moisturization and moisture retention, reducing secretion and pores contraction, rejuvenating effect), essential oils have been successfully used to improve the skin condition.

Vitamins help to eliminate open pores, wrinkles, eczema, darkenings. They improve metabolism, accelerate and simplify the absorption of nutrients, thereby increasing the skin tonicity: reduced tonicity is the reason that causes withering of the skin and wrinkle formation [2].

When purchasing cosmetic product, the consumer is particularly interested in naturalness of this product. At present, only a small proportion of available on the market are produced from natural raw materials.

Enrichment of skincare cosmetic oil with natural vegetable oils and natural vegetable extracts allows for combining both healing and cosmetic properties in one product.

As biologically active additives, we can use herbal extracts and essential oils that have a beneficial effect on the human skin covering. Such properties are characteristic of rosehip $\mathrm{CO}_{2}$ extract and oil.

The use of rosehip oil is conditioned by high contents of vitamins A, D, E, F, phospholipids, tocopherols, fatty acids, macro and micronutrients and other biologically active substances. It also contains significant amounts of fatty acids such as Omega-3, Omega-9 and Omega-6 that protect the skin from UV rays, keep the moisture in cells and enhance the tissue regeneration capacity, preventing wrinkle formation, as well as palmitic acid which stimulates the production of hyaluronic acid, collagen and elastin by the skin cells [5,6].

Research covered rosehip fruits wild-growing in western Georgia.

We extracted the freeze-dehydrated samples by superfluid extraction. At the first stage, the fat fraction was separated. The following parameters were used to maximize fat extrusion: pressure - 300 bar, temperature $-40{ }^{\circ} \mathrm{C}, \mathrm{CO}_{2}$ delivery rate $-1.2 \mathrm{kgph}$ and duration of extraction - 3 hours. At the second stage, hydrophilic extract was obtained by means of a co-solvent ethyl alcohol (in relation to 20\%-carbon dioxide), optimum extraction condition: pressure 300 bar, $\mathrm{CO}_{2}$ delivery rate $-4 \mathrm{kgph}$. The resulting extract was concentrated in a vacuum evaporator at a pressure of $0.65 \mathrm{~atm}$ and at a temperature of $40{ }^{\circ} \mathrm{C}$.

Fat yield ranges from 8.12 to $10.17 \%$. The refractive index of fat obtained is 1,4782 units.

The dry rosehip hydrophilic extract is a dark yellow powder, rich in secondary metabolites - phenols, mainly in flavonoids. The amount of total phenols was determined using the Folin-Ciocalteu reagent, while the total flavonoids content was determined by the $\mathrm{AlCl}_{3}$ 
reagent using the spectrophotometric method. Antioxidant activity of dry hydrophilic extract was determined by DPPH method [7,8,9].

Table 1

Biologically active compounds of dry rosehip hydrophilic extract and their antioxidant activity

\begin{tabular}{|c|c|}
\hline \multicolumn{2}{|c|}{ Dry rosehip hydrophilic extract $-100 \%$} \\
\hline $\begin{array}{c}\text { Total phenols } \\
\mathrm{mg} / 100 \mathrm{~g} \text { on dried basis }\end{array}$ & 3032 \\
\hline $\begin{array}{c}\text { Flavonoids } \\
\mathrm{mg} / 100 \mathrm{~g} \text { on dried basis }\end{array}$ & 1501 \\
\hline $\begin{array}{c}\text { Antioxidant activity, } \% \\
\text { Dissolution rate } \mathrm{F}=75\end{array}$ & 54 \\
\hline
\end{tabular}

High antioxidant activity of dry rosehip hydrophilic extract allows us for using it in cosmetic oils as a stabilizer and preservative.

Among the promising avenues is the use of rosehip fruit extract and oil in the composition of cosmetic oil, as a result of the skin becomes moist, dense, smooth and has a nice appearance. Due to the presence of the plant components, every person senses that there is the lrevitalizing power of flowers and plants.

\section{References}

1. Voskanyan O.S. The properties of liposomes and their use in cosmetology / O.S. Voskanyan, D.A. Guseva. - M.: PISHCHEPROMIZDAT publishers, 2015. - 184 p.

2. Georgievsliy V.P. Biologically active substances of plant origin. /B.N. Golovkin, R.N. Rudenskaya, I.A. Trofimova and others - NAUKA publishers, 2002. - 1014 p.

3. Inés Mármol; Cristina Sánchez-de-Diego; Nerea Jiménez-Moreno; Carmen AncínAzpilicueta; María Jesús Rodríguez-Yoldi. „Therapeutic Applications of Rose Hips from Different Rosa Species“. International Journal of Molecular Sciences . 2017 Jun;

4. Barros L., Carvalho A.M.,Ferreira I.C.F.R. Exotic fruits as a source of important phytochemicals: Improving the traditional use of Rosa canina fruits in Portugal // Food Research international. 2011. Vol.44. N7. Pp.2233-2236. 
5. A. Kunicka-Styczyńska, M. Sikora, D. Kalemba, International Journal of Cosmetic Science, 1, 53-61 (2011).

6. S. H. Kim, S. Y. Lee, C. Y. Hong, K. S. Gwak, , International Journal of Cosmetic Science, 5, 484-490, (2013).

7. Augusto T.R. Phenolic compounds and antioxidant activity of hydroalcoholic extracts of wild and cultivated murtilla (Ugnimolinae Turcz) // Food Sci. Technol. 2014. Vol. 34, N 4. P. 667673

8. Mussatto S.I. Extraction of antioxidant phenolic compounds from spent coff ee grounds // Sep. Purif. Technol. 2011. Vol. 83. P. 173-179

9. Roman1 I., Stănilă A. Bioactive pounds and antioxidant activity of Rosa canina L. biotypes from spontaneous fl ora of Transylvania // Chem. Centr. J. 2013. Vol. 7, N 73. P. 3-7. 